\title{
Educação: inclusão ou exclusão?
}

Vânia de Menezes ${ }^{1}$

Resumo: A questão da inclusão de pessoas com necessidades especiais em todos os recursos da sociedade ainda é muito incipiente no Brasil. $\mathrm{Na}$ perspectiva da inclusão, devemos pensar a educação como um processo de formação humanística e profissionalizante destes, criando possibilidades para uma vida digna e sustentável. Diante do exposto, este artigo tem como objeto de estudo a inclusão no sistema educacional brasileiro, e como objetivo geral discutir as barreiras que dificultam este trabalho e ao mesmo tempo analisa meios de acessibilidade que propicie a capacitação esperada por meio de um possível trabalho em conjunto das escolas de educação básica com as Instituições de Ensino Superior. Para tanto, faz uma discussão da realidade em questão. E por último avalia a importância do sistema educacional brasileiro em todos os âmbitos para que este projeto se conclua de fato.

Palavras-chave: educação; Inclusão social; Capacitação; Acessibilidade

Abstract: The issue of inclusion of people with special needs in all society's resources is still very incipient in Brazil. From the perspective of inclusion, we must think of education as a process of humanistic and

${ }^{1}$ Licenciada e bacharel em ciências sociais (2009) pela Universidade Estadual de Maringá (UEM). Professora Especialista em Docência do Ensino Superior (2012) pela Faculdade de Tecnologia América do Sul. Professora Especialista em Educação do/no Campo (2013) pela Faculdade Eficaz e Professora Especialista em Educação Especial (2013) pela Faculdade de Tecnologia América do Sul. Atualmente tem experiência na área de educação, com ênfase em sociologia, antropologia e ciências política, atuando como docente pela Secretaria Estadual de Educação do Estado do Paraná-SEED-PR (2010). Residente no município de Maringá-PR/BR. E-mail: vaniarpm@ yahoo.com.br 
vocational training of these, creating opportunities for a dignified and sustainable life. Given the above, this article has as object of study inclusion in the Brazilian educational system, and as a general objective to discuss the barriers that hinder this work while analyzing media accessibility that provides the expected empowerment through a possible joint work of the elementary schools with Institutions of Higher Education. To do so, makes a discussion of the reality in question. And finally evaluates the importance of the Brazilian educational system at all levels so that this project is actually complete.

Keywords: Education; Social Inclusion; Training; Accessibility

\section{Introdução}

Há milênios, a história ilumina que os direitos humanos manisfestam-se na vida real de forma desigual para grupos sociais e pessoas distintas. Mulheres, negros, indígenas, pessoas com deficiência entre outros grupos em desvantagem econômica na sociedade. Muito se tem ouvido nos últimos tempos acerca da palavra inclusão, seja na mídia, nos espaços educacionais, ou mesmo nas instituições especializadas para pessoas com deficiência.

Para DINIZ (2007), a concepção de deficiência como uma variação do normal da espécie humana foi uma criação discursiva do século XVIII, e desde então ser deficiente é experimentar um corpo fora da norma. O corpo com deficiência somente se delineia quando contrastado com uma representação de o que seria o corpo sem deficiência. Ao contrário do que se imagina, não há como descrever um 
corpo com deficiência como anormal. A anormalidade é um julgamento estético e, portanto, um valor moral sobre os estilos de vida.

É importante ressaltar que a estrutura das sociedades, desde os seus primórdios, sempre inabilitou os portadores de deficiência, marginalizando-os e privando-os de liberdade. Essas pessoas, sem respeito, sem atendimento, sem direitos, sempre foram alvo de atitudes preconceituosas e ações impiedosas.

Movimentos nacionais e internacionais têm buscado o consenso para a formatação de uma política de integração e de educação inclusiva, sendo que o seu ápice foi a Conferência Mundial de Educação Especial, que contou com a participação de 88 países e 25 organizações internacionais, em assembleia geral, na cidade de Salamanca, na Espanha, em junho de 1994. Neste, não se resolveu todos os problemas de marginalização dessas pessoas, no entanto, ampliou as discussões em torno da acessibilidade e refletiu possíveis caminhos para uma futura inclusão.

É importante destacar que a ação de movimentos sociais diversos já eliminou ou minimizou inúmeras barreiras para promover e ampliar os direitos humanos de grupos sociais vulneráveis. Contudo, ainda persiste a desigualdade traduzida na falta de oportunidades de acesso à educação de qualidade, necessária para realizar o pleno desenvolvimento de cada indivíduo e sua cidadania (FERREIRA, 2006). 


\section{A inclusão no sistema educacional brasileiro}

Relatórios internacionais estimam que, em torno de $10 \%$ da população mundial, é constituída por pessoas com deficiência, a maioria das quais vive em países economicamente pobres. No Brasil, o CENSO Demográfico de 2000, do Instituto Brasileiro de Geografia e Estatística, revela que $14,5 \% 1$ da população brasileira apresenta algum tipo de incapacidade ou deficiência.

Pensando na inclusão, a atual Lei de Diretrizes e Bases para a Educação Nacional, Lei no 9.394, de 20/12/1996, trata, especificamente, no Capítulo V, da Educação Especial. Define-a por modalidade de educação escolar, oferecida preferencialmente na rede regular de ensino, para pessoas com necessidades educacionais especiais. Assim, ela perpassa todos os níveis de ensino, desde a Educação Infantil ao Ensino Superior. Como ilustra a figura a seguir: 
Figura 1: A Educação Especial e o Sistema Educacional Brasileiro

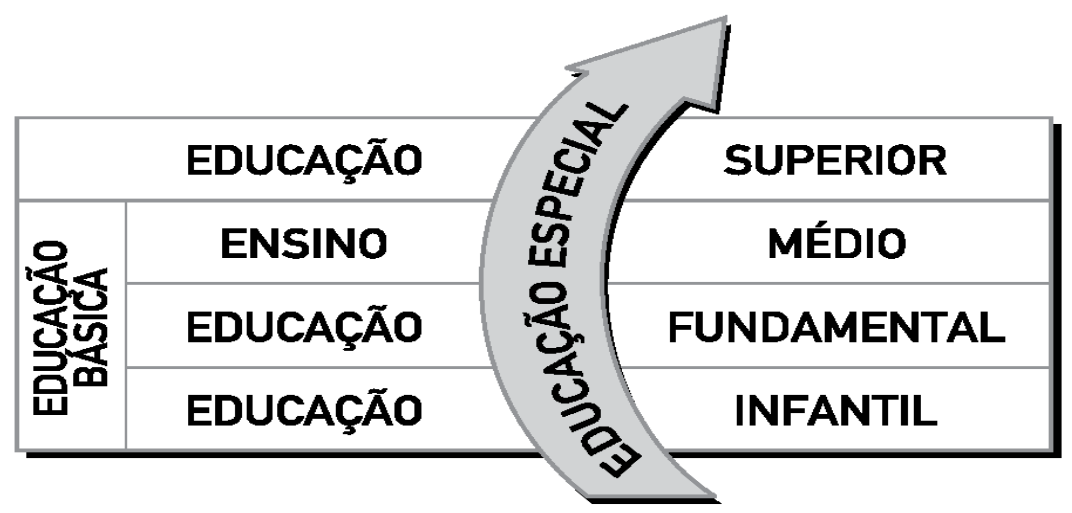

Fonte: Brasil (2006, p. 6)

Contudo na prática, dados oficiais do (MEC/SEESP, 2008) indicam que, embora as matrículas estejam aumentando na rede de ensino, as condições educacionais se mantêm desiguais para os estudantes com deficiência: com muita frequência, aprendizes com deficiência são discriminados nas escolas brasileiras quando não têm o acesso aos recursos e apoios de que necessitam, para estudarem em condições de igualdade em relação aos seus colegas.

JANNUZZI (2006), em seus estudos já ressaltava que desde o século XVI, durante a colonização do país, até o início do século XX, a educação do deficiente praticamente nem existia, sendo pouco a pouco desenvolvida com o apoio de pessoas interessadas, mas respaldadas por um governo de segundas intenções. A educação do deficiente se concentrava basicamente no ensino de trabalhos manuais aos mesmos, 
na tentativa de garantir-lhes meios de subsistência e assim isentar o Estado de uma futura dependência desses cidadãos.

A autora ainda afirma que em 1890, após a realização de uma reforma nos métodos educacionais do Instituto Benjamim Constant (anteriormente denominado Imperial Instituto dos Meninos Cegos), o eixo científico começa a ser um pouco valorizado no ensino do deficiente. A referência para a normalidade passa a ser o posicionamento no rendimento escolar, e não havia qualquer orientação que balizasse o tratamento dos ditos "anormais". Assim, embora a ênfase fosse a educação em coletividade, os alunos com desenvolvimento atípico eram segregados em diferentes salas de aula para que não ocorressem interferências no ritmo de aprendizado dos demais alunos. Durante esse período histórico, educava-se em nome da “ordem e progresso", na tentativa de evitar que deficientes não educados se tornassem criminosos ou perturbadores da ordem social.

\section{Inclusão na educação brasileira: Inclusão ou exclusão?}

Para CARVALHO (2009), os documentos já produzidos acerca da educação, tais como a Constituição, a Declaração Universal dos Direitos Humanos, a Declaração Mundial sobre Educação para Todos, Satisfação das Necessidades Básicas de Aprendizagem, a Declaração de Salamanca e Linha de Ação, dentre tantas outras, 
apresentam as ideias fundamentais para que se elaborem propostas de educação inclusiva.

A globalização da economia traz em seu bojo uma maior competitividade e desigualdades entre os países dificultando, ainda mais, a efetivação de projetos educacionais inclusivos. Desse modo, somente estar contido nos textos das leis e documentos oficiais os princípios da inclusão, não garante sua concretização. Como afirma Carvalho (2009), "mais que prever há que prover recursos de toda a ordem, permitindo que os direitos humanos sejam respeitados, de fato" (p.79). Fundamentado nesse ideal, um sistema de educação inclusivo deve efetivar:

O direito à educação; o direito à igualdade de oportunidades, o que não significa um "modo igual" de educar a todos e sim dar a cada um o que necessita, em função de suas características e necessidades individuais; escolas responsivas e de boa qualidade; o direito de aprendizagem; e o direito à participação. (CARVALHO, 2009. p.81)

Assim como Carvalho, BAPTISTA (2009), ao estudar o assunto em questão, também aponta evidencias de que a educação inclusiva possui fatores fortes da diversidade que se apresenta para enriquecer o ambiente educacional. Todavia, ressalta a importância do diálogo e do debate a respeito do assunto e a necessidade de mudanças no sistema escolar e ao finalizar sua reflexão, levanta pontos para 
discussão que precisam ser analisados no objetivo de se constituir uma inclusão realmente positiva e efetiva.

Sabemos que uma dos maiores problemas enfrentados no Brasil é a falta de conhecimento que faz com que a deficiência seja considerada uma doença crônica, um peso ou um problema. Essa situação se intensifica junto aos mais carentes, pois a falta de recursos econômicos diminui as chances de um atendimento de qualidade. No plano de governo, o que se vê são programas, propostas, projetos, leis e decretos com lindas e sonoras siglas, que ficam, na maioria das vezes, só no papel. Programas similares e simultâneos são lançados em duas ou três pastas, sem que haja integração de objetivos e metas entre eles.

Nos estados e municípios, não existe uma política efetiva de inclusão que viabilize planos integrados de educação, com metas e ações convergindo para a obtenção de um mesmo objetivo: resguardar o direito das pessoas com deficiência.

A realidade inclusiva na educação brasileira tem mostrado que os ciclos do ensino fundamental, com sua passagem automática de ano, e a falta de formação de professores, de recursos técnico-pedagógicos, de estímulo suplementar, de acompanhamento de equipe multidisciplinar - fonoaudiólogos, assistentes sociais, psicólogos, terapeutas ocupacionais -, de salas e de professores de apoio deixam a questão da inclusão escolar sem estrutura eficiente, bonita apenas na teoria. 
Considerando os paradigmas conceituais e princípios que vem sendo progressivamente defendidos em documentos Nacionais e Internacionais. A inclusão é um movimento mundial de luta das pessoas com deficiências e seus familiares na busca de seus direitos e lugar na sociedade. A inclusão vem buscando a não exclusão, propõe ações que garantam acesso e permanência no ensino regular.

Educar para uma sociedade "inclusiva" pressupõe compreender toda uma complexa realidade presente nas salas de aula. Realidade na qual os educadores se encontram e sentem-se, muitas vezes, despreparados quando a questão é trabalhar com alunos que têm algum tipo de deficiência.

Dentro dessa perspectiva, é necessário um estudo que busque avaliar as possibilidades que visem à inclusão desejada, com um possível levantamento de alternativas, que apontem os recursos pedagógicos e de acessibilidade que eliminem as barreiras de continuidade destes nos estudos, considerando suas necessidades específicas.

\section{Inclusão: Uma prática possível}

Em nome da igualdade de atendimentos, muitos teóricos radicais defendem a inclusão escolar de forma simplista: é só colocar esse aluno na classe comum e tudo se resolve. Entretanto, suas teses não refletem a realidade de que as pessoas com deficiência possuem 
necessidades educativas especiais e, assim, pouca contribuição têm trazido para todos os envolvidos na questão.

Deve-se lembrar, sempre, que o princípio fundamental da sociedade inclusiva é o de que todas as pessoas com deficiência devem ter suas necessidades especiais atendidas. É no atendimento das diversidades que se encontra a democracia.

SKLIAR (1997-1998) ao analisar a inclusão, reconhece que as diferenças precisam ser consideradas em uma política educacional que busca garantir o acesso à educação enquanto direito humano. Dessa forma, não está se tratando de oposições, mas de diferentes vieses que se tornam fundamentais para uma análise político educacional do sistema de ensino, da sua estrutura e de seus currículos. As diferenças passam a fazer a diferença ao se refletir sobre a educação em cada contexto histórico-cultural nos diferentes espaços. $\mathrm{O}$ dito normal não mais configura a realidade, uma vez que a normalidade passa a ser relativizada perante os diferentes grupos sociais e culturais que caracterizam uma sociedade multicultural. Nesse sentido, a educação de crianças especiais passa a fazer parte de uma preocupação muito mais ampla. Ser diferente e as consequências implicadas nestas diferenças é que devem ser matéria de reflexão e análise ao se pensar em educação para todos.

Outro ponto interessante ressaltar é a necessidade de uma verdadeira integração professor-aluno, é necessário que o professor da sala regular e os especialistas de educação das escolas tenham 
conhecimento sobre o que é deficiência, quais são seus principais tipos, causas, características e as necessidades educativas de cada deficiência. O professor precisa, antes de tudo, ter ampla visão desta área, que deve ser proveniente de sua formação acadêmica. Hoje, poucas escolas e universidades, que formam professores, abordam adequadamente a questão da deficiência em seus currículos.

Antes mesmo de se pensar em inclusão, era preciso pensar em um trabalho em conjunto com as Instituições de Educação de Ensino Superior incluindo esta nos currículos dos cursos de licenciaturas, julgase aqui, que a preparação do docente para enfrentar esta realidade em sala de aula dentro das escolas de educação básica seja mais que uma prioridade, tendo em vista a importância do mesmo.

\section{Inclusão na educação básica e no ensino superior: um trabalho unificado}

No ano de 2004, o Ministério Público Federal publica o documento $O$ Acesso de Alunos com Deficiência às Escolas e Classes Comuns da Rede Regular, com o objetivo de disseminar os conceitos e diretrizes mundiais para a inclusão, reafirmando o direito e os benefícios da escolarização de alunos com e sem deficiência nas turmas comuns do ensino regular. Já se passaram 10 anos e ainda hoje é visível as debilidades na execução deste. 
Após este documento, houve uma explosão de cursos de pósgraduação em Educação Especial para a demanda. Todavia, o projeto foi colocado em prática sem colocar em consideração que faltava capacitação e formação dos profissionais da educação para a demanda, talvez, seja este um fator que tornou o projeto falho.

Neste faltou considerar também alguns pontos importantes, tais como, qual é o papel da inclusão, quais são as metas a serem alcançadas com esta, quais são as parcerias necessárias para efetivação do projeto, adequação de todos os ambientes escolares seja de infraestrutura ou recursos para a chegada dos mesmos, o que pode ser feito para preparação dos docentes já graduados e atuantes no sistema de ensino básico e superior e, uma proposta de mudanças no currículo dos cursos de licenciaturas em todas as Instituições de Ensino Superior que vise à capacitação de docentes para a demanda, enfim... Se estes pontos foram pensados e refletidos não cabe aqui questionar, o fato é se pensados? Houve um equívoco no momento de colocá-los em prática, tendo em vista a realidade já abordada até aqui.

Para que os alunos com deficiência possam dar continuidade nos estudos, é preciso e necessário, um trabalho unificado entre o ensino básico com o ensino superior, no sentido que prepare os futuros docentes para a demanda, o que se tem atualmente, são cursos criados de pós-graduação para atender estes, todavia, a debilidade no projeto ainda tem continuidade por meio dos cursos de licenciatura nas Instituições de Ensino Superior. A proposta defendida aqui é a 
necessidade de mudança dos currículos dos cursos de licenciatura incluindo a capacitação dos docentes para inclusão. Cabe lembrar que, uma sociedade inclusiva tem o compromisso com as minorias e a democracia só concretizará de fato, se estes estiverem incluídos.

Mediante todo o exposto, fica evidente que a criação da lei, não serve como garantia da mesma se não houver ações que visem o preparo antes mesmo da implementação. O êxito da política de inclusão de alunos com deficiência no ensino depende, em primeiro lugar, de uma mudança na educação como um todo, desde a preparação dos ambientes, levando em consideração a infraestrutura e os recursos pedagógicos como também a preparação de profissionais fora e dentro dos cursos de licenciaturas para a demanda.

\section{Referências:}

BAPTISTA, Cláudio Roberto (org.) Inclusão e Escolarização: Múltiplas Perspectivas. Porto Alegre: Mediação, 2009;

BRASIL. MEC. Lei de Diretrizes e Bases da Educação Nacional Brasileira (Lei 9394 de 20 de Dezembro de 1996). Ministério da Educação. Brasília, DF, 2001 a;

BRASIL. MEC/SEE. Política Nacional de educação Especial na Perspectiva da Educação Inclusiva. Brasília: Revista Inclusão, v.4, n ${ }^{\circ}$ 1 , 2008 , Disponível em: 
http://portal.mec.gov.br/index.php?option=com_docman\&task. Acesso em: 08/08/2014;

BRASIL. MEC/SEESP. Diretrizes Nacionais para a Educação Especial na Educação Básica. (Conselho Nacional de Educação, Resolução no. 02 de 11 de setembro de 2001). Ministério da Educação. Secretaria de Educação Especial. DF, 2001b. Disponível em: <http://portal.mec.gov.br/seesp/arquivos/pdf/diretrizes.pdf $>$.

Acesso em: 01/08/2014.

BRASIL. Ministério Público Federal: Fundação Procurador Pedro Jorge de Melo e Silva (org.) O Acesso de Alunos com Deficiência às Escolas e Classes Comuns da Rede Regular. $2^{\mathrm{a}}$ ed. rev. e atualiz. Brasília: Procuradoria Federal dos Direitos do Cidadão, 2004. Disponível em: <http://www.paulofreire.org/wpcontent/uploads/2012/Ed_Inclusiva/cartilha_acesso_deficientes.pdf $>$. Acesso em: 08/08/2014.

CARVALHO, Rosita Edler. Educação Inclusiva: com os pingos nos “is". Porto Alegre: Mediação, 2009.

DINIZ, Débora. O que é deficiência? Coleção Primeiros Passos. Rio de Janeiro: Brasiliense, 2007.

FERREIRA, Windyz Brazão. Educar na Diversidade: práticas educacionais inclusivas na sala de aula regular. In Ensaio Pedagógicos, Educação Inclusiva: direito à diversidade. Secretaria de Educação Especial. Ministério da Educação. Brasília, Distrito Federal, 2006. 146 p. pp. 125-132. (ISBN 978 - 85 - 60331 - 00 -0).

IBGE. CENSO Demográfico, 2000. Instituto Brasileiro de Geografia e Estatística. 2000. 
JANNUZZI, Gilberta de Martino. A educação do deficiente no Brasil: dos primórdios ao início do século XXI. Campinas, SP: Autores Associados, 2006.

SKLIAR, C. (Org.) A surdez: um olhar sobre as diferenças. Porto Alegre: Editora Mediação. 1998.

(Org.) Educação e exclusão: Abordagens Sócioantropológicas em educação especial. Porto Alegre: Mediação, 1997, p.7 a 79 . 